\title{
3-D finite element analysis of roller-expanded heat exchanger tubes in over-enlarged tubesheet holes
}

\author{
N. Merah • A. Al-Aboodi • A. N. Shuaib • \\ Y. Al-Nassar
}

Received: 6 March 2011 / Accepted: 18 December 2011 / Published online: 3 January 2012

(C) The Author(s) 2011. This article is published with open access at Springerlink.com

\begin{abstract}
Repeated de-stubbing and re-tubing of heat exchangers in petrochemical plants during their useful lifetime may result in over-enlarged tubesheet holes with overtolerances that exceed those prescribed by Tubular Exchanger Manufacturing Association (TEMA) standards (1988). Roller expansion of tubes in these over-enlarged holes may result in tube thinning and weakening of the joint due to a decrease of interfacial pressure between the tube and tubesheet. In the present work, a 3-D finite element (FE) model of a tube-tubesheet joint was used to determine displacement and stress distributions along the axial direction of roller expanded tube-tubesheet joint and to evaluate the combined effects of large initial clearance and strain hardening of tube material on interfacial pressure and tube deformation. The results obtained from the present model are compared to those of axisymmetric FE analysis and to the experimental results. Both axisymmetric and 3-D models are found to yield comparable trends showing that for elastic perfectly plastic tube material the residual contact pressure remains constant well above the prescribed TEMA maximum overtolerance values. In addition, both models show that for strain hardening tube materials the interfacial pressure increases with increasing clearance. An appreciable difference is observed at high overtolerances where the 3-D model predicts cut-off clearances (clearance at which the interfacial pressure
\end{abstract}

N. Merah $(\bowtie) \cdot$ A. N. Shuaib · Y. Al-Nassar

Mechanical Engineering Department,

King Fahd University of Petroleum and Minerals,

Dhahran 31261, Saudi Arabia

e-mail: nesar@kfupm.edu.sa

A. Al-Aboodi

Mechanical Engineering Department, Qassim University, PO Box 6677, Buraydah 51452, Saudi Arabia starts to drastically drop) which are about $30 \%$ lower than those predicted by the axisymmetric models. The tube inner surface deformation and pull out forces estimated from 3-D results compares very well with those obtained from the experimental tests.

Keywords 3-D Finite element - Tube-tubesheet joint rolling $\cdot$ Clearance effects $\cdot$ Strain hardening .

Overtolerances

\section{Introduction}

The frequent process of de-stubbing and re-tubing operations performed during the life of the heat exchangers in petrochemical and energy producing plants results in the over enlargement of the tubesheet hole to levels that may exceed the levels prescribed by industrial standards (Standard of the Tubular Exchanger Manufacturer Association 'TEMA' 1988). When new tubes are installed, they are often expanded using the rolling process into the enlarged tubesheet holes; this may result in a deterioration in the strength of tube-tubesheet joint having large initial clearance as well as in the strain hardening and thinning of the expanded tubes and their surrounding ligaments.

Simulation of roller expanding of tubes into tubesheet by the finite element method is associated with a number of difficulties such as roller kinematics and the absence of loading axisymmetry. In fact, the mechanical rolling process is a good example of periodic symmetry with respect to the load application. A number of researchers have shown that the complexity of the tube-tubesheet roller expansion can be simplified by reducing it to an axisymmetric quasi-static problem (Aufaure 1987; Merah et al. 2010, 2009; Updike et al. 1992; Merah 2008; Al-Aboodi et al. 2009; Cizelj and 
Mavko 1995; Williams 1996, 2003). Displacements are applied in steps up to the required expansion and then decreased down to zero such that the tube-tubesheet contact ensures the strength of the connection joint after transmitting a large radial stress to tube's outer surface. Andrieux and Voldoire (1995) developed an axisymmetric FE model to simulate roller expansion using five steps. Cizelj and Mavko (1995) used the axisymmetric model in ABAQUS code to evaluate the residual stresses in one-step rolled tube to tubesheet joint. Williams (1996), used three load steps to complete the final mechanical roll expansion. Because of the absence of loading symmetry other researchers, however have used 3-D finite element models to simulate roller expansion of tube-tubesheet joints (Williams 1997; Metzger et al. 1995). These models which are more realistic provide more in-depth information about the displacement and stress distributions in all directions Williams however, concluded that the 3-D model did not bring any additional information when compared to axisymmetric model (Williams 1997).

To the authors' knowledge the effect of tube-tubesheet initial clearance on the strength of tube/tubesheet joint has not been addressed by 3-D FE analysis of roller expansion. Existing work has relied mainly on axisymmetric models with hydraulic expansion (Allam et al. 1998) or with roller expansion (Al-Aboodi et al. 2008, 2009; Cizelj and Mavko 1995; Williams 1996).

In this paper, a 3-D FE model has been utilized in a major commercial finite element analysis code (ANSYS 2004) to simulate the roller expansion and study residual deformation and stress distributions to show the effect of initial clearance and tube material on the residual contact pressure between the tube and tubesheet. Initial clearances within and beyond the prescribed TEMA range (Standard of the Tubular Exchanger Manufacturer Association 'TEMA' 1988) have been considered. Low-to-high tube and tubesheet material strain hardening properties have also been included in the study and their effects discussed herein. The 3-D model results pertaining to the effect of clearance on interfacial pressure are compared with those obtained from the axisymmetric simulation of the same effects and validated using experimental results developed earlier by Shuaib et al. (2003).

\section{Geometry and 3-D FE Model}

The equivalent sleeve diameter determined earlier by Shuaib et al. (2003) for the stabilizer feed/bottom exchanger was implemented in the 3-D model. Figure 1a illustrates the geometry and dimensions of the model of tube-tubesheet joint under study. Figure $1 \mathrm{~b}$ shows the full 3-D model mesh and Fig. 1c a 2-D view of the model with boundary conditions on the primary side.

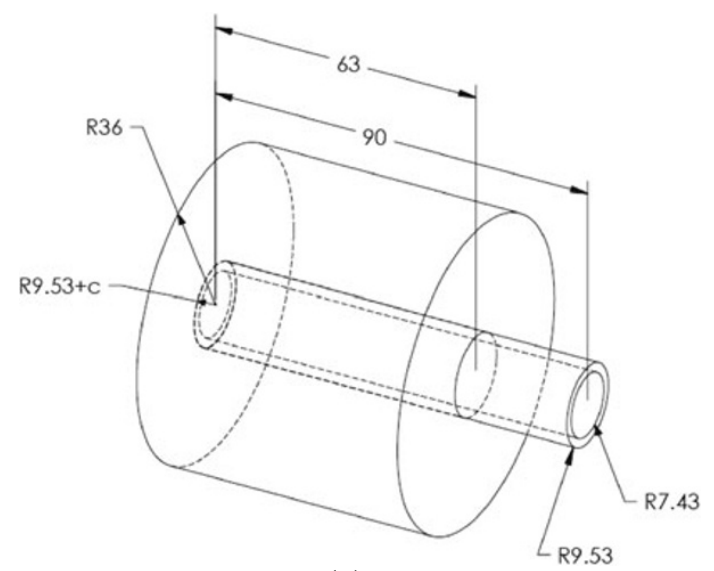

(a)

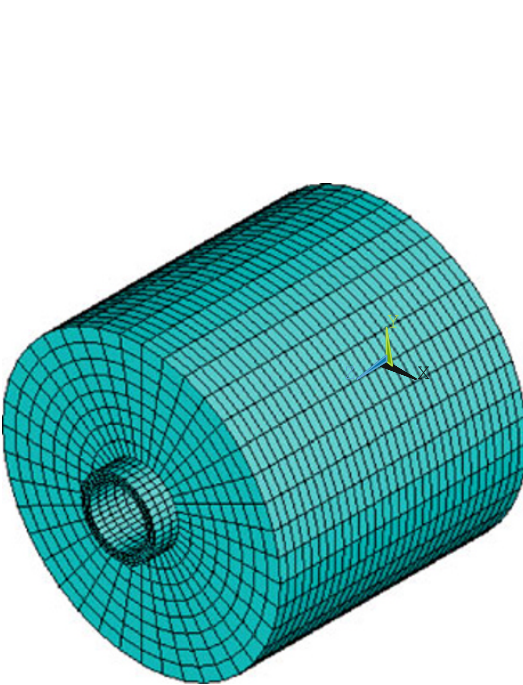

(b)

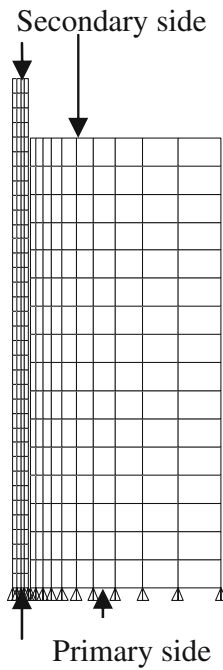

(c)
Fig. 1 Geometry and FE mesh of the model. a Tube and tubesheet assembly with dimensions in millimeters, $\mathbf{b}$ full 3-D model mesh and c 2-D representation showing boundary conditions on primary side

Meshing of tube and tubesheet is performed using 3-D structural solid element ANSYS-SOLID 186 which has a quadratic displacement behavior and is well suited for modeling irregular meshes. The element is defined by 20 nodes having three degrees of freedom each: translations in the nodal $x, y$, and $z$ directions. The element is chosen here because it supports plasticity, hyperelasticity, and large deflections. The model of Fig. 1b has 8,000 elements and 9,920 nodes. The level of refining was tested to establish effective meshed models. It was found that refining the mesh beyond 8,000 elements did not add any significant precision to the solution.

The contact element CONTA174 is used to represent contact and sliding between 3-D "target" surfaces (TARGE170) and a deformable surface, defined by this element. The element is applicable to 3-D structural and coupled field contact analyses. This element is located on 
the surfaces of 3-D solid elements with mid-side nodes. It has the same geometric characteristics as the solid element face with which it is connected. Contact occurs when the element surface penetrates one of the target segment elements (TARGE170) on a specified target surface. A sensitivity analysis was performed in order to select the real constants values such as those defining tolerance and offset between the contact and target elements (Al-Zayer 2001; Al-Aboodi 2006).

Joint materials

The elastic-plastic behavior of tube and tubesheet material is represented by bilinear curves. In the experimental work used here for validation, the tube is seamless, cold-drawn, low-carbon steel-type ASTM 179 and the tubesheet material is carbon steel-type ASTM A5 16 G70 with average yield stress of $248 \mathrm{MPa}$ and modulus of elasticity of $207 \mathrm{GPa}$ (Al-Aboodi et al. 2008; Shuaib et al. 2003).

Because of expected large plastic strains, the Bilinear Isotropic Hardening (BISO) option was used in the 3-D FE model. The curve in the plastic region was approximated by a linear relationship. The slope of the approximated line in the plastic region of the true stress-strain diagram defines the tangent modulus of plasticity $\left(E_{\mathrm{tt}}\right)$. An elasticperfectly plastic material is that having zero tangent modulus. The average value of $E_{\mathrm{tt}}$ for the tube material used in the experimental study was found to be $733 \mathrm{MPa}$ (Al-Aboodi et al. 2008). In order to investigate the effect of tube material strain hardening on the residual stresses, $E_{\mathrm{tt}}$ values ranging from 0 to $1.2 \mathrm{GPa}$ were considered (Table 1). These values were chosen to cover the plastic behavior of most of the steel materials used in similar applications. Table 1 contains the input parameters to FE code of the analysis. They consist of the range of clearances (c), percentage wall reductions (\%WR), and tube and tubesheet material constants. The friction coefficient between the tube and tubesheet is assumed to be zero (Merah et al. 2003; Al-Zayer 2001).

Table 1 Input parameters for 3-D FE model

\begin{tabular}{ll}
\hline Parameter & $\begin{array}{l}\text { Value or range of } \\
\text { values }\end{array}$ \\
\hline Initial clearance, $c$ & $0-4.5 \mathrm{~mm}$ \\
Wall reduction (\%WR) & $5 \%$ \\
Tube and tubesheet material elastic modulus, $E$ & $207 \mathrm{GPa}$ \\
Tube and tubesheet material yield stress & $248 \mathrm{MPa}$ \\
Poisson's ratio, $v$ & 0.3 \\
Tangent modulus, $E_{\mathrm{tt}}$ & $0,0.4,0.8$ \\
& and $1.2 \mathrm{GPa}$ \\
\hline
\end{tabular}

Simulation of rolling

Rolling is performed by the rigid rollers that stay in contact with the inner surface of the tube being expanded. During expansion the rollers are modeled as rigid lines that undergo outward radial displacement and simultaneous circumferential motion that simulate tube expansion kinematics. According to the industrial rolling practice specified by a major roller expansion equipment manufacturer (Cooper Power Tools 2005), the amount of the radial displacement $\left(u_{\mathrm{r}}\right)$ of the rigid rollers against the tube inner surface during the tube expansion phase is obtained from the values of the required tube percent wall reduction $(\% \mathrm{WR}=5 \%)$, the tube thickness $(t)$, and initial tubetubesheet clearance $(c=0-4.5 \mathrm{~mm})$ as follows:

$u_{\mathrm{r}}=(\% \mathrm{WR}) t+c$.

Once the expansion process reaches this limit of radial deformation, the inner tube surface will be released. The rolling process is simulated by three rigid rollers, $120^{\circ}$ apart, moving circumferentially by increments of $6^{\circ}$. Four revolutions are required to reach the maximum radial displacement determined by Eq. 1. The rolling process is described schematically in Fig. 2a. Graphical representation of the displacement profile along the circumference of the inner tube is shown in Fig. 2b. Figure 3 shows that for each roller, it is assumed that a total of 11 nodes are effectively deformed. Five nodes on each side of the roller are partially displaced plus the middle node along the generating line. Equation 2 is used to define the deformation profile yielding maximum displacement at the mid node. It is a sinusoidal function that represents the shape of the inner tube surface displaced by the radial movement of the roller.

$u_{i}=u_{\mathrm{s}} \mathrm{e}^{-\beta_{i}}\left(\sin \left(\beta_{i}\right)+\cos \left(\beta_{i}\right)\right)$

where $u_{i}$ is the nodal displacement at the $i$ th node, $u_{s}$ is the step displacement and $\beta_{i}$ is a normalized nodal factor taking the values $0,0.25,0.5,0.75,1.0$, and $1.25 ; \beta_{i}=0$ corresponds to the mid point.

The boundary condition in this model was applied by constraining the primary side of tube from moving axially (Fig. 1c) and the outer side of the tube at its secondary side from moving tangentially. The model used in the current investigation did not require that the analysis includes the effects of torsional moments, because the tube was constrained from rotation. The local tangential strain was found to be insignificant compared to the global radial strain (Al-Aboodi 2006). This is due to the fact that the roller is sliding inside the tube as in Williams (1997) and Metzger et al. (1995). This reduces the amount of friction and tangential strain.

Similar to the work of Williams (1997) four rolling revolutions and two smoothing revolutions were used. No 
Fig. 2 a Schematic representation of the industrial rolling process (Cooper Tools 2005), b Graphical representation of rolling process in the present model

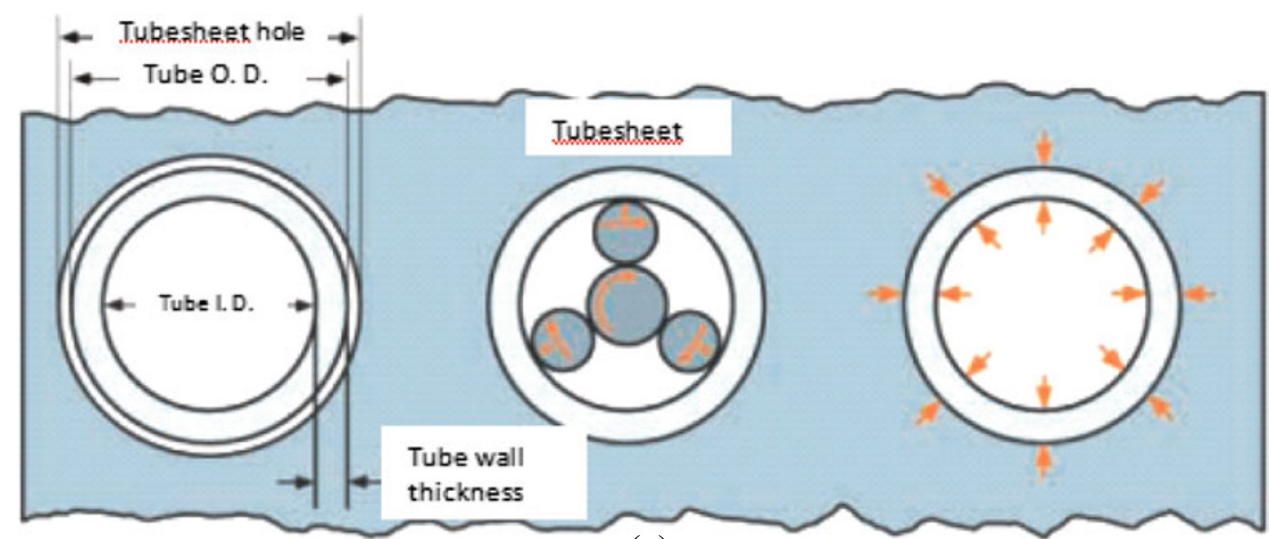

(a)

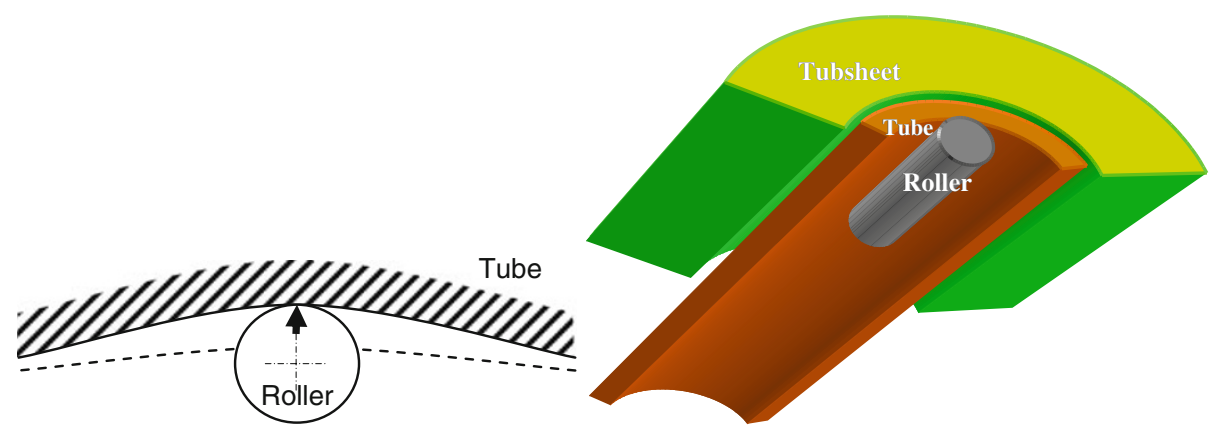

(b) radial displacement is assigned during the smoothing process. To take into account the non-linear response of tube material in the elastic-plastic transition region and in the plastic zone the step size is determined using a non linear equation. The proposed relation yields a large step size in the elastic region and smaller and smaller sizes in the plastic region. The mathematical representation of such trend can be expressed in logarithmic profile as:

$u_{\mathrm{s}}=\frac{u_{t} \ln (n)}{N}$

where $u_{\mathrm{s}}$ is the step radial displacement, $n$ is the step number, and $N$ is the total number of steps.

\section{Results and discussions}

This section discusses the results on the deformation and stress distributions along the roller expanded length and transition zone in tube-tubesheet joint as well as the effect of large clearance values on the interfacial stresses. Figure 4 shows the tube inner and outer surface radial deformations along the tubesheet width at the end of the loading and unloading events. The radial displacement of the inner tube surface is indicated by $u_{\mathrm{ri}}$ and that of the outer surface by $u_{\mathrm{ro}}$. Similar to what was reported in earlier

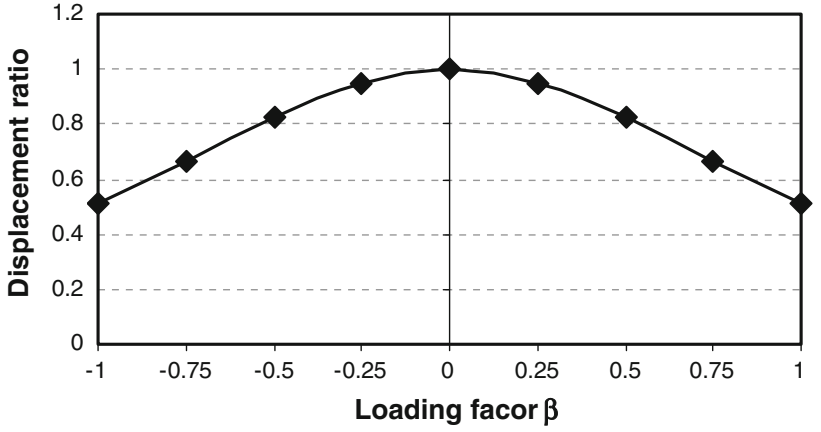

Fig. 3 Displacement profile due to roller expansion

work using 2-D axisymmetric model (Merah et al. 2010) inner and outer radial displacements for $5 \%$ wall reduction and an initial clearance of $0.127 \mathrm{~mm}$ remain constant in most of the $47.25 \mathrm{~mm}$ expanded length. A disturbance in the $u_{\mathrm{ri}}$ distribution happens in the transition zone (i.e. zone between the expanded and unexpanded areas of the tube). As will be explained later, this disturbance will have an effect on the stress distributions. Releasing the load caused the inner tube surface to spring back from a maximum of 0.232 to $0.188 \mathrm{~mm}$ resulting in radial strain of about $0.45 \%$ and that of the outer surface from 0.190 to $0.151 \mathrm{~mm}$.

To experimentally validate these results tube diameters were measured before and after rolling. Several 
measurements were made for tube material having similar value of tangent modulus, $E_{\mathrm{tt}}$, joint geometry and configuration, tube-tubesheet clearance, and loading condition (i.e. $E_{\mathrm{tt}}=0.74 \mathrm{GPa}, \mathrm{WR}=5 \%$ and $c=0.12 \mathrm{~mm}$ ). A micrometer was used to measure inner diameters of a number of tubes before and after expansion to determine the average value of the inner surface radial deformation. The thick dashed line in Fig. 4 shows the average value of the measured tube inner surface radial deformation $(0.185 \mathrm{~mm})$. It is clear that the present 3-D FE model yields an excellent representation of the deformed inner surface.

Figure 5 illustrates the distributions of stress components on the tube's inner and outer surfaces along the axial direction after the retraction of the rollers for the condition of $5 \% \mathrm{WR}$ and $0.127 \mathrm{~mm}$ radial clearance. The stresses include $\sigma_{\mathrm{r}}, \sigma_{\theta}, \sigma_{\mathrm{y}}, \sigma_{\text {eqv }}, \sigma_{\text {cont }}$ which are the radial, tangential, axial, equivalent and contact stresses, respectively. The stresses corresponding to the tube's outer surface display a behavior similar to that of the radial displacement shown in Fig. 4. These stresses remain uniform along most of the expanded length and redistribute in the transition zone between the fully expanded and the unexpanded tube. At the end of the rolled tube length, the radial, axial and tangential stress components $\left(\sigma_{\mathrm{r}}, \sigma_{\mathrm{z}}, \sigma_{\theta}\right)$ exhibit two inflection points where they drop first and then increase very sharply in the transition zone. This behavior is attributed to the tube deformation elbow in this area (Fig. 4).

Due to tubesheet spring back after releasing the load, the hoop stress $\left(\sigma_{\theta}\right)$ on both inner and outer surfaces is found to be compressive in most of the rolled tube length, but becomes tensile in the transition zone where it reaches a value of about half the yield strength of the material on the inner surface of the tube. The axial stress which remains very small in magnitude on both surfaces becomes tensile on the inner surface in the transition zone as well after

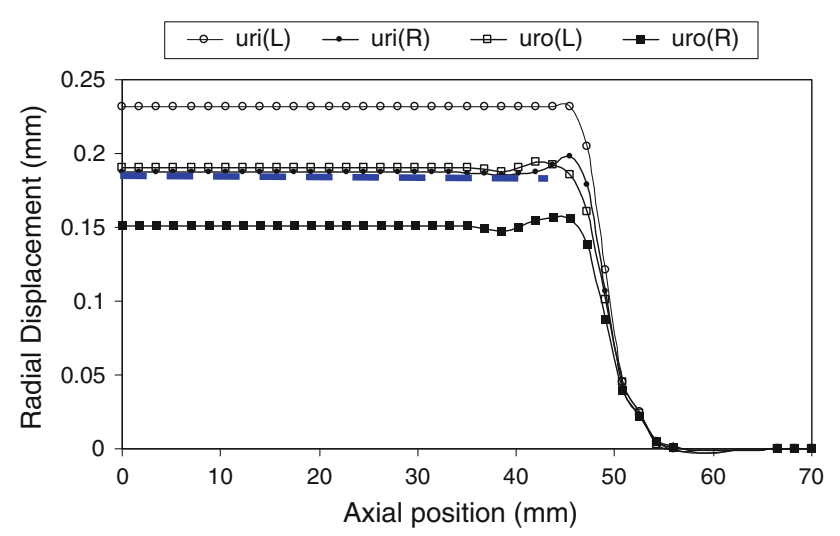

Fig. 4 Loaded (L) and residual (R) radial displacement at the tube inner and outer surfaces $\left(E_{\mathrm{tt}}=0.8 \mathrm{GPa}, 5 \% \mathrm{WR}\right.$, and $\left.c=0.127 \mathrm{~mm}\right)$ roller retraction, reaching a value of $100 \mathrm{MPa}$. It should be noted that the tensile hoop and axial stress maxima happen at the same axial position around $8 \mathrm{~mm}$ from the end of the rolled area (Fig. 5b). This is somehow different from what was reported by Williams (1997). The existence of high tensile hoop and axial stresses in this region when coupled with expected tensile hoop stress from inner fluid pressure make it a critical design zone that needs proper attention especially when using aggressive fluids.

Analysis of the tube's outer surface stress distribution after roller retraction showed that $\sigma_{\mathrm{z}}$ reaches an average tensile stress value of $9 \mathrm{MPa}$ which drops to $5 \mathrm{MPa}$ upon the release of load which are very small compared to $\sigma_{\mathrm{r}}$ and $\sigma_{\theta}$ and emphasizes the assumption of this case as a plane stress model. The contact stress which reached an average compressive value of $160 \mathrm{MPa}$ after the last loading step drops to $61 \mathrm{MPa}$ upon unloading (Fig. 5a). Because this stress is a measure of the joint strength its variation with initial clearance and material strain hardening is studied in detail in the following section.

Effect of clearance and tube material strain hardening on residual contact stress

The combined effects of clearance and tube material strain hardening on the average value of radial stress for $5 \%$ wall reduction obtained from the 3-D finite element model are illustrated in Fig. 6. As can be seen, the clearance range considered in this study is well above the TEMA overtolerance limit. Similar to what was observed in axisymmetric model results by Al-Aboodi et al. (2008) for strain hardening tube materials $\left(E_{\mathrm{tt}}>0 \mathrm{GPa}\right)$, the residual contact stress gradually increases with the increase in radial clearance before dropping at lower cut-off clearances. The increase in residual contact stress with increase in $E_{\mathrm{tt}}$ is due to higher tube material strength resisting tubesheet material spring back.

As illustrated in Fig. 7, the 3-D model resulted in lower critical (cut-off) clearances for both types of tube materials $\left(E_{\mathrm{tt}}=0 \mathrm{GPa}\right.$ and $\left.E_{\mathrm{tt}}=1.2 \mathrm{GPa}\right)$ and higher contact stresses for strain hardening material than the axisymmetric model. This discrepancy comes from the difference between the calculated wall reduction and the actual one. The same value of input displacement will result in lower value of actual percent wall reduction for the 3-D model because of the extra tangential displacement in the 3-D model. Subsequently, the critical clearance will be higher for axisymmetric model.

\section{Experimental validation of contact stress}

In the experimental work the joint strength is measured in terms of pull-out or push-out force. The pull-out force $F$ is 

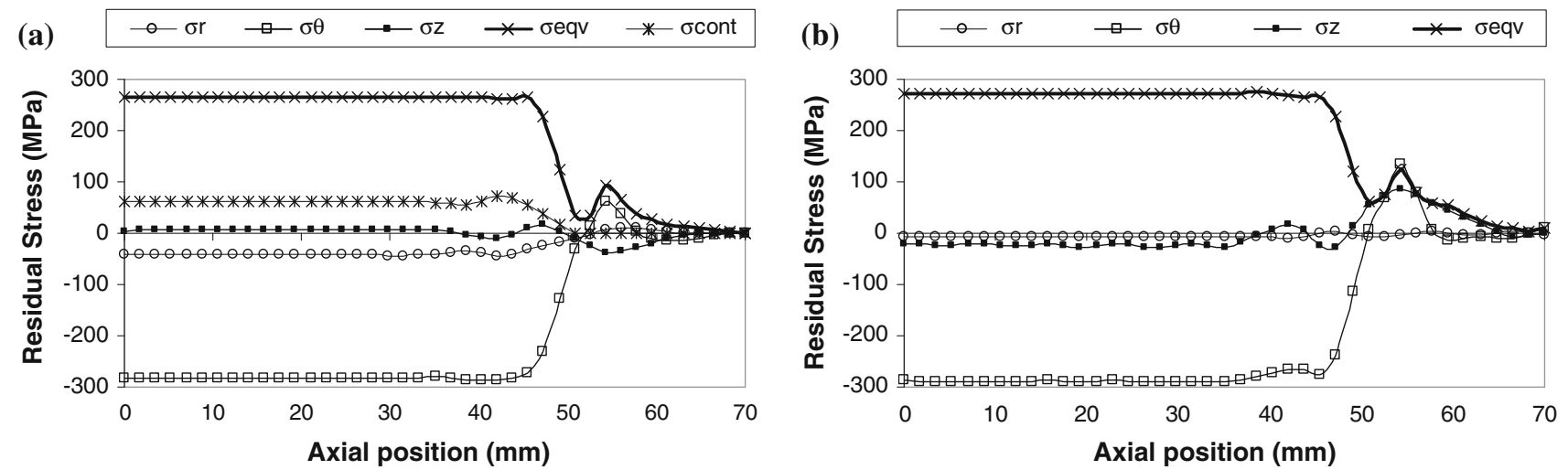

Fig. 5 Stress distributions on the (a) outer and (b) inner tube surfaces after unloading $\left(E_{\mathrm{tt}}=0.8 \mathrm{GPa}, 5 \% \mathrm{WR}\right.$, and $\left.c=0.127 \mathrm{~mm}\right)$

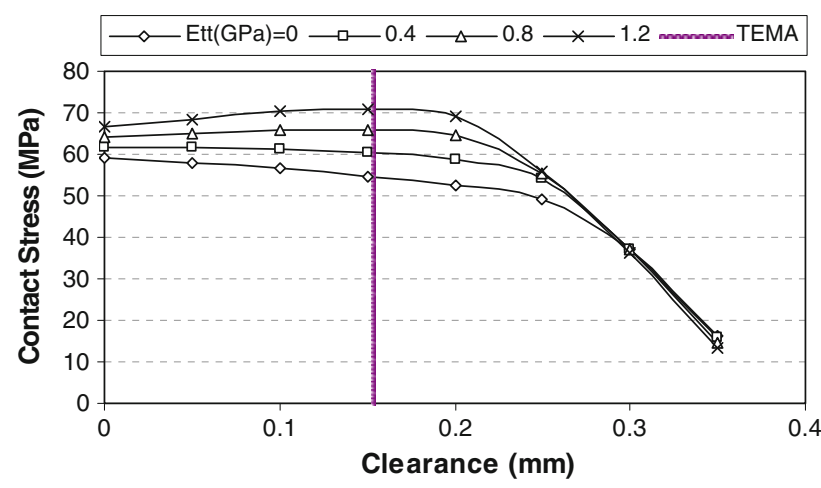

Fig. 6 Effects of material strain hardening and clearance on contact stress for $5 \% \mathrm{WR}$

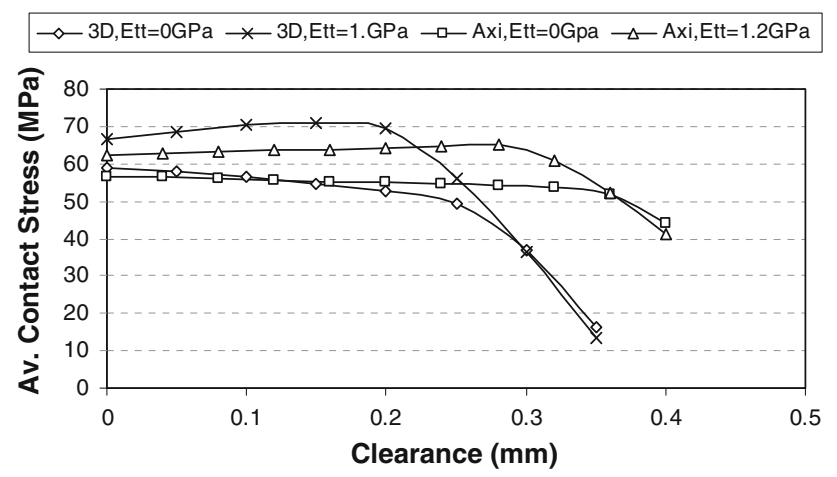

Fig. 7 Comparison of axisymmetric and 3-D contact stress variation with clearance for different materials and for $\mathrm{WR}=5 \%$

directly proportional to the residual contact stress, $\sigma_{\mathrm{c}}$, and the expanded length, $l$, (Scott et al. 1984; Jawad et al. 1987).

$F=2 \pi \mu \sigma_{\mathrm{c}} r_{\mathrm{o}} l$

where $r_{o}$ is the outer radius of the tube, and $\mu$ is the friction coefficient. The development of the above equation is based

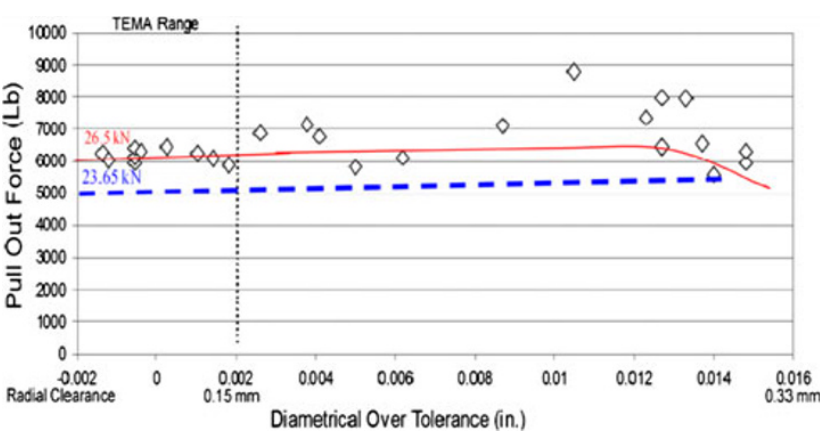

Fig. 8 Comparison of pull-out force estimated by 3-D model to axisymmetric and experimental results

on the assumption that the expanded tube can be pulled or pushed out of the tubesheet by a force $(F)$ equal to the friction force $\left(F_{\mathrm{f}}=2 \pi \mu \sigma_{\mathrm{c}} r_{\mathrm{o}} l\right)$ between the outer surface of the tube and the inner wall of the tubesheet hole. Two major challenges have to be dealt with when applying this equation to estimate the pull-out force; the friction coefficient and the contact stress. Different researchers have used different values for the friction coefficient. Metzger et al. (1995) used a value of 0.2. Allam and Bazergui (2002) developed an experimental set up and measured an average friction coefficient of 0.1375 . The average value of the residual contact (radial) stress is usually used to estimate the pull out force (Merah et al. 2009; Merah 2008; Al-Aboodi et al. 2009; Shuaib et al. 2003; Al-Aboodi 2006). To validate the FE results, the pull out force $F$ was computed using the contact stress determined by the 3-D model and $\mu=0.1375$, for $E_{\mathrm{tt}}=0.8 \mathrm{GPa}$ and compared to that obtained experimentally by Shuaib et al. (2003) as well as to that determined from the axysmmetric model (Merah 2008). The material used in experimental program has an $E_{\mathrm{tt}}$ of $0.733 \mathrm{GPa}$. Using the empirical value of 0.1375 , an outer tube radius of $9.525 \mathrm{~mm}$, an expanded length of $47.25 \mathrm{~mm}$ the pull-out 
force is estimated to be between 23.65 and $26.5 \mathrm{kN}$ within the TEMA (1988) clearance range. It can be seen from Fig. 8 that the pull-out force estimated from the 3-D model compares very well with the average value of the pull-out force obtained from the experimental tests (Shuaib et al. 2003).

\section{Conclusion}

A 3-D finite element model is developed and utilized to investigate the radial displacement and stress distributions along the axial direction as well as the effect of radial clearance and tube material on the strength of a rolled tube-tubesheet stabilizer feed/bottom exchanger. The radial deformation distribution of inner and outer tube surfaces was uniform in most of the expanded tube length. A sudden increase in radial displacement is observed at the end of the expanded length (in the transition area). Similarly, inner tube surface residual axial and hoop stresses are found to be uniform and compressive along the expanded length and tensile in the transition zone between the expanded and the unexpanded tube regions. Both maximum tensile stresses happen at about $8 \mathrm{~mm}$ from the end of expanded length. The circumferential stress is predominant reaching a value around one-half the yield strength of the tube material. This, when combined with service load and corrosive environment is expected to cause longitudinal cracks.

The effect of clearance on residual interfacial pressure determined using the 3-D model is compared to that of axisymmetric FE model. Both models are found to yield comparable results showing that for elastic perfectly plastic tube material the residual contact pressure remains almost constant well above the prescribed TEMA maximum overtolerance values. In addition, both models show that for strain hardening tube materials the interfacial pressure increases with increasing clearance; with 3-D model predicting higher radial stress values. An appreciable difference is observed at high overtolerances where the 3-D model predicts cut-off clearances (clearance at which the interfacial pressure starts to drastically drop) which are about $30 \%$ lower than those predicted by the axisymmetric model. The experimental validation proved that the present 3-D model allowed a more realistic estimation of the inner tube wall deformation and pull out force.

Acknowledgments The authors thankfully acknowledge the support of the King Fahd University of Petroleum and Minerals. The second author acknowledges the support of Qassim University.

Open Access This article is distributed under the terms of the Creative Commons Attribution License which permits any use, distribution and reproduction in any medium, provided the original author(s) and source are credited.

\section{References}

Al-Aboodi A (2006) Finite element analysis of roller expanded tubetubesheet joints with overenlarged tubesheet holes. $\mathrm{PhD}$ thesis, KFUPM

Al-Aboodi A, Merah N, Shuaib AR, Al-Nassar Y, Al-Anizi SS (2008) Modeling the effects of initial tube-tubesheet clearance, wall reduction and material strain hardening on rolled joint strength. ASME J Press Vessel Technol 130/4:041204-1-041204-6

Al-Aboodi A, Merah N, Shuaib AN, Al-Nassar Y (2009) FEA of groove geometry effect on roller and hydraulically expanded tube to tubesheet joint strength. Int $\mathrm{J}$ Precis Technol 1(2):201-207

Allam M, Bazergui A (2002) Axial strength of tube-to tubesheet joints: finite element and experimental evaluations. J Press Vessel Technol 124:23-31

Allam M, Chaaban A, Bazergui A (1998) Estimation of residual stresses in hydraulically expanded tube-to-tubesheet joints. J Press Vessel Technol 120:129-137

Al-Zayer A (2001) Analytical and finite element investigation of initial clearance effect on tube-to-tubesheet joint strength. MSc thesis, KFUPM

Andrieux S, Voldoire F (1995) Stress identification in steam generator tubes from profile measurements. Nucl Eng Design 158:417-427

ANSYS (2004) Version 9.0, program and help documentations, Swanson Analysis System, Inc.

Aufaure M (1987) Analysis of residual stresses due to roll-expansion process: finite element computation and validation by experimental tests. In: Transaction of the 9th international conference of SMIRT, pp 499-503

Cizelj L, Mavko B (1995) Propagation of stress corrosion cracks in steam generator tubes. Int J Press Vessel Piping 63:35-43

Cooper Power Tools (2005) Tube cleaners and expanders airetool ${ }^{\circledR}$ manual. SP-1100EN0405-410M

Jawad MH, Clarkin EJ, Schuessler RE (1987) Evaluation of tube-totubesheet junctions. J Press Vessel Technol 109:19-26

Merah N, Al-Zayer A, Shuaib A, Arif A (2003) Finite Element evaluation of clearance effect on tube-to-tubesheet joint strength. Int J Press Vessel Piping 80:879-885

Merah N, Al-Aboodi A, Shuaib AN, Al-Nassar Y, Al-Anizi SS (2009) Combined effects of tube projection, initial tube-tubesheet clearance and tube material strain hardening on rolled joint strength. ASME J Press Vessel Technol 131/5

Merah N, Al-Aboodi A, Shuaib AN, Al-Nassar Y (2010) 3-D FEA of the effects of large overtolerances on roller expanded tubetubesheet joint strength. In: Abstract published on IVth European conference on computational mechanics, Paris 16-21, 2010

Metzger DR, Sauve RG, Nadeau E (1995) Prediction of residual stress by simulation of the rolled joint manufacturing process for steam generators, PVP vol 305. In: Current topics in computational mechanics. ASME, New York

Scott DA, Wolgemuth GA, Aikin JA (1984) Hydraulically expanded tube-to-tubesheet joints. J Press Vessel Technol 106:104-109

Shuaib AN, Merah N, Khraisheh MK, Allam IM, Al-Anizi SS (2003) Experimental investigation of heat exchanger tubesheet hole enlargement. J Press Vessel Technol 125:19-25

Standard of the Tubular Exchanger Manufacturer Association 'TEMA', 7th edn (1988) TEMA, Terrytown

Updike DP, Kalnins A, Caldwell SM (1992) Residual stresses in transition zone of heat exchanger tubes. J Press Vessel Technol 114:149-156

Williams DK (1996) Prediction of residual stresses in the mechanically expanded $0.750^{\prime \prime}$ diameter steam generator tube plugs-part 1:2-D solution, PVP vol 327. In: Residual stresses in design, fabrication, assessment and repair, ASME, New York, pp 173-180 
Williams DK (1997) Prediction of residual stresses in the mechanically expanded $0.750^{\prime \prime}$ diameter steam generator tube plugspart 2: 3-D solution, PVP vol 354. In: Current topics in the design and analysis of pressure vessels and piping. ASME, New York, pp 17-28
Williams DK (2003) Prediction of residual stresses in the mechanical roll of HX tubes into TEMA grooves, PVP vol 2003-1937. In: Design and analysis methods and fitness for service, ASME, New York, pp 121-29 